\title{
Análisis jurídico sobre la ejecución de políticas ambientales
}

\section{Legal analysis on the implementation of environmental policies}

\author{
Alba Rosa Pupo-Kairuz \\ uq.albapupo@uniandes.edu.ec \\ Universidad Regional Autónoma de los Andes, Quevedo \\ Ecuador \\ https://orcid.org/0000-0002-1719-9250 \\ Nancy Cecilia Zapata-Jaramillo \\ dq.nancyczj52@uniandes.edu.ec \\ Universidad Regional Autónoma de los Andes, Quevedo \\ Ecuador \\ https://orcid.org/0000-0002-3767-1137
}

Recepción: 15 de septiembre 2021

Revisado: 25 octubre 2021

Aprobación: 15 de noviembre 2021

Publicación: 01 de diciembre 2021 


\section{Estimado Editor (a):}

En la actualidad, los Gobiernos Municipales gozan de autonomía política, administrativa y financiera, y a su vez tienen la facultad de ejecutar políticas ambientales con la finalidad de regular, prevenir y controlar la contaminación ambiental dentro de sus competencias exclusivas. Sin embargo, la ausencia de compromiso político para desarrollar y emplear una política ambiental, así como también la débil aplicación de sanciones por la inobservancia legal ambiental, evita garantizar a los ciudadanos un ambiente sano para su supervivencia. la naturaleza es susceptible de vulneraciones tanto en nivel nacional e internacionales, así como también históricamente ha tenido un uso irracional de sus recursos renovables y no renovables, y que en la actualidad la falta de concientización por parte del ser humano ha causado su deterioro ambiental. En este sentido, Zambrano Noles, Goyas Céspedes y Serrano Cayamcela(2018) plantean:

La atención a la problemática ambiental y creación de políticas ha evolucionado desde los inicios de los llamados de los conservacionistas ante la extinción de especies y la preservación del mundo natural, hasta la consideración de manejo sostenido de recursos, primero como ecodesarrollo y posteriormente como desarrollo sustentable(p235)

Los distintos niveles de gobiernos a nivel nacional, deben ejecutar y dictar las políticas ambientales dentro de su circunscripción, ya que estas deben ser incorporadas en toda planificación o proyecto que lleve a cabo tanto instituciones públicas o privadas, ya que de esta manera se logra brindar una prestación de servicio eficiente y de calidad, teniendo como finalidad mejorar la calidad vida y conservar los principios naturales de los humanos, así como también el Estado garantizará un desarrollo sostenible (social, económico y medioambiental.

En pocos siglos, debido a los interés políticos y económicos, la modernidad ha logrado devastar los recursos renovables y no renovables de forma virulenta e irracional, al punto de poner en riesgo la coexistencia de varios seres vivos y, por consiguiente, la propia existencia del ser humano. Por lo tanto, pese a existir una norma constitucional que ampara jurídicamente los derechos de la naturaleza, y leyes orgánicas, su cumplimiento ha sido un arduo trabajo, ya que prima el interés político y económico. 
En concordancia del artículo 395 numeral 2 de la Constitución, articulo 54 literal k) del Código Orgánico de Organización Territorial, Autonomía y Descentralizada 2010, se determina la facultad de que tiene los Gobiernos Autónomos Descentralizados Municipales, para regular, prevenir y controlar la contaminación ambiental en el territorio cantonal de manera articulada con las políticas ambientales nacionales. En correlación al Código Orgánico Ambiental (2018), en el cual se determina:

Articulo 3. Literal 2. La política nacional ambiental deberá estar incorporada obligatoriamente en los instrumentos y procesos de planificación, decisión y ejecución, a cargo de los organismos y entidades del sector público.

Dentro del ordenamiento jurídico vigente en el Estado ecuatoriano reconoce a la naturaleza como sujeta de derecho, derechos direccionados al respeto, reparación y restauración de la misma al ser vulnerada por el accionar humano, y al igual, los niveles de gobierno subnacionales tienen el deber de dictar las políticas ambientales dentro de su circunscripción, mismas que serán conforme a las que dicta la autoridad ambiental nacional.

De modo que, la ausencia de compromiso político en la falta de ejecución de políticas ambientales, por parte del Gobierno Municipal del Cantón Mocache no permite la prevención y control de contaminación, las cuales deben incorporarse en toda planificación o proyecto que efectué este nivel de gobierno, con la finalidad de lograr el cumplimiento del Régimen del Buen Vivir. En este sentido, la Constitución del (2008) determina en:

Artículo 395 numeral 2. Las políticas de gestión ambiental se aplicarán de manera transversal y serán de obligatorio cumplimiento por parte del Estado en todos sus niveles y por todas las personas naturales o jurídicas.

En la actualidad, el Código Orgánico Ambiental es el cuerpo legal vigente y que tiene por objeto garantizar el cumplimiento de los derechos y garantías constitucionales, de los cuales gozan todos los individuos de la especie humana, siendo aquellos que, bajo el régimen del Buen Vivir adoptado por la Constitución del 2008, busca mantener un equilibrio entre el ser humano y la naturaleza. La vigencia de este código desde el 2018, deroga a la ley de Gestión Ambiental, misma que fue promulgada en 1999. Por 
ende, las políticas ambientales son aquellas que deben implementarse por los distintos niveles de gobiernos existentes en el Ecuador, cuyo objeto consiste en que el Estado debe adoptar lineamientos ambientales en el uso racional de los recursos renovables y no renovables, por tanto, la protección ambiental también deberá estar presente en la ejecución de obras públicas o en cualquier accionar por personas naturales y jurídicas. Entre ellas, la Ley Orgánica para la Planificación Integral de la Circunscripción Territorial Especial Amazónica. Y sobre todo tal como establece la Constitución esta ley contiene e incluye aspectos sociales, económicos, ambientales y culturales propios de la amazonia. Tomando en cuenta un adecuado ordenamiento territorial para proteger adecuadamente los ecosistemas amazónicos ecuatorianos, enmarcado toda esta normativa, planes y disposiciones en el sumak kawsay o buen vivir (Gracia Panta, Bermeo Reyes, y Rodríguez Mera, 2019).

Mediante el fundamento teórico y legal, se ha evidenciado que los gobiernos autónomos descentralizados, a consecuencia de ser Ecuador, un país que se gobierna de manera descentralizada, trasfiere competencias y facultades desde el gobierno central a estos niveles de gobiernos subnacionales, con el objeto de dar cumplimiento a la política ambiental nacional dictada por la Autoridad Ambiental Nacional, mediante un Sistema Único de Gestión Ambiental, lo cual permite garantizar un ambienta sano y ecológicamente equilibrado en todo el territorio nacional, y a su vez busca equilibrar entre lo económico, social y ambiental.

\section{FINANCIAMIENTO}

No monetario.

\section{AGRADECIMIENTO}

A la Universidad Regional Autónoma de los Andes, Quevedo, por motivar el desarrollo de la Investigación. 


\section{REFERENCIAS CONSULTADAS}

Asamblea Nacional Constituyente de la República del Ecuador, (2008). Constitución de la República del Ecuador. [Constitution of the Republic of Ecuador]. Montecristi. Registro Oficial 449 de 20-oct-2008. Recuperado de https://n9.cl/sia

Asamblea Nacional del Ecuador. (2011). Código Orgánico de la Función Judicial. [Organic Code of the Judicial Function]. Quito: Registro Oficial Suplemento 544. Recuperado de: https://n9.cl/wm40

Asamblea Nacional Constituyente. (2010). Código orgánico de organización territorial Autonomía y descentralización. [Organic code of territorial organization Autonomy and decentralization]. Registro Oficial Suplemento 303 de 19-oct2010 Recuperado de: https://n9.cl/d9vg

Asamblea Constituyente. (2017). Código Orgánico del Ambiente. [Organic Environment Code]. Quito, Pichincha, Ecuador: Registro Oficial 983.

Corte Constitucional del Ecuador, Sentencia № 3-19 CN/20 Caso № 3-19-CN (Error Inexcusable) (Corte Constitucional del Ecuador. [Constitutional Court of Ecuador] Recuperado de: https://n9.cl/97a4

Gracia Panta, E., Bermeo Reyes, J., y Rodríguez Mera, L. (2019). Promoción de valores y políticas organizacionales a partir del derecho público en instituciones de seguridad ciudadana. [Promotion of organizational values and policies based on public law in citizen security institutions]. IUSTITIA SOCIALIS, 4(7), 156161. doi: http://dx.doi.org/10.35381/racii.v4i7.369

Zambrano Noles, S., Goyas Céspedes, L., y Serrano Cayamcela, J. (2018). Políticas públicas en defensa de la naturaleza, casuística y penalidad en Ecuador. [ Public policies in defense of nature, casuistry and penalty in Ecuador]. Revista Universidad y Sociedad, 10(2), 234-250. Recuperado de: https://n9.cl/i83rl 